\title{
Outcomes of full-endoscopic posterior cervical foraminotomy for cervical radiculopathy caused by bony stenosis of the intervertebral foramen
}

\author{
Kazuo Ohmori, Koichiro Ono, Takeshi Hori \\ Center for Spinal Surgery, Nippon Koukan Hospital, Kanagawa 210-0852, Japan.
}

Correspondence to: Dr. Kazuo Ohmori, Center for Spinal Surgery, Nippon Koukan Hospital, 1-2-1, Koukandori, Kawasaki-ku, Kawasaki City, Kanagawa 210-0852, Japan. E-mail: kazuospine@gmail.com

How to cite this article: Ohmori K, Ono K, Hori T. Outcomes of full-endoscopic posterior cervical foraminotomy for cervical radiculopathy caused by bony stenosis of the intervertebral foramen. Mini-invasive Surg 2017;1:63-8.

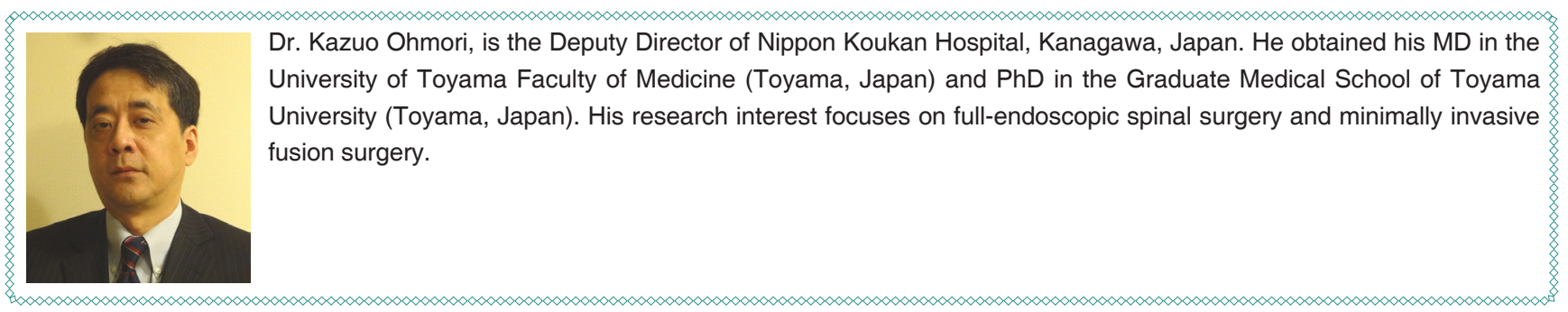

Article history:

Received: 05-03-2017

Accepted: 24-04-2017

Published: 30-06-2017

Key words:

Full endoscopic surgery,

cervical radiculopathy,

foraminotomy,

bony stenosis of the intervertebral foramen

\begin{abstract}
Aim: Full-endoscopic posterior cervical foraminotomy (FPCF) has been utilized to treat cervical lateral disc herniation and provided good surgical outcomes. The authors examined the superiority of FPCF in patients with spondylotic foraminal stenosis. Methods: Fifty-nine cases of FPCF were evaluated. Of the 59 patients, 34 had lateral disc herniation (group H) and 25 had spondylotic foraminal stenosis (group S). Operative time, complications, length of hospital stay, visual analog pain scale scores of neck and arm pain, and the amount of facet joint resection were compared between the groups. Results: The mean operative times were $96 \mathrm{~min}$ (group H) and $100 \mathrm{~min}$ (group S). The lengths of hospital stay were 3.0 days and 3.9 days, respectively. No significant differences were observed in pre-operative neck and arm pain between the groups. Average neck pain at the final follow-up was significantly less severe in group $H$ (2.9) than in group S (12). However, postoperative arm pain was the same after surgery in both groups (14). In both groups, $52 \%$ of the facet joint was resected. Conclusion: The surgical outcome of FPCF in patients with spondylotic foraminal stenosis is equivalent to that in patients with lateral disc herniation.
\end{abstract}

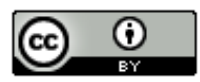

This is an open access article licensed under the terms of Creative Commons Attribution 4.0 International License (https://creativecommons.org/licenses/by/4.0/), which permits unrestricted use, distribution, and reproduction in any medium, as long as the original author is credited and the new creations are licensed under the identical terms.

For reprints contact: service@oaepublish.com

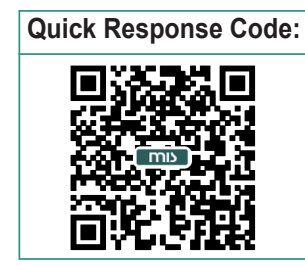




\section{INTRODUCTION}

The upper extremity pain experienced by patients with cervical radiculopathy is commonly caused by either lateral cervical disc herniation or stenosis of the intervertebral foramen due to a bone spur resulting from spondylosis. Surgical treatment of cervical radiculopathy can be divided into two procedures: anterior cervical decompression and fusion ${ }^{[1-4]}$ or posterior foraminotomy. ${ }^{[5-9]}$ The latter option involves three types of procedures: open, ${ }^{[5-9]}$ microscopic $^{[10,11]}$ and micro-endoscopic surgery. ${ }^{[12-16]}$

The use of full-endoscopic posterior cervical foraminotomy (FPCF) to treat lateral disc herniation was first reported by Ruetten et al. ${ }^{[17,18]}$ in 2007 . They concluded that FPCF is a sufficient and safe supplement and alternative to conventional procedures. Since then, Kim et al. ${ }^{[19,20]}$ also suggested FPCF is an alternative to open surgery. However, there has been no comparison of FPCF outcomes in patients with cervical lateral disc herniation versus those with bony stenosis of the intervertebral foramen. Therefore, the aim of this study was to compare clinical outcomes of FPCF in these two groups of patients.

\section{METHODS}

We retrospectively assessed 59 consecutive patients [45 men, 14 women; mean age 53.7 (30-81) years] who underwent FPCF for cervical radiculopathy between October 2014 and July 2016. All patients had either a single-level symptomatic lateral disc herniation or bony stenosis of the intervertebral foramen, none of which were recurrent. Conservative therapy was pursued for at least 3 months before surgery. The indication for surgery was persistent radicular pain or neurological deficits. Among the 59 patients, the affected level was C4/5 ( $n=16), C 5 / 6(n=25), C 6 / 7(n=16)$, and C7/T1 $(n=2)$. Thirty-four patients had lateral disc herniation (group $\mathrm{H}$ ), and 25 had bony stenosis of the intervertebral foramen (group S). All diagnoses were confirmed on preoperative computed tomography (CT) scans and magnetic resonance imaging (MRI).

The variables assessed and compared between groups $\mathrm{H}$ and $\mathrm{S}$ included operative time, complications, length of hospital stay, visual analog pain scale (VAS) scores of pre-and postoperative neck and arm pain, and the amount of facet joint resection. The percentage of facet joint resection was measured on the coronal plane of postoperative CT images that revealed the widest bone removal [Figure 1].

Clinical and radiographic parameters were statistically analyzed with Mann-Whitney $U$ and chi-square tests.

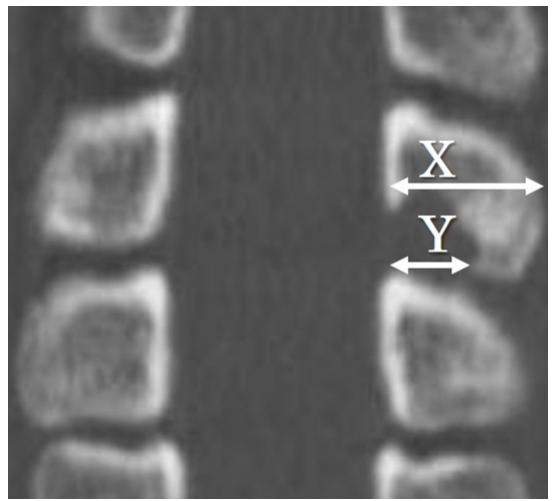

Figure 1: Percentage of resection of the facet joint was calculated by $\mathrm{Y} / \mathrm{X} \times 100 \%$ which was measured on the coronal plane on postoperative computer tomography scans
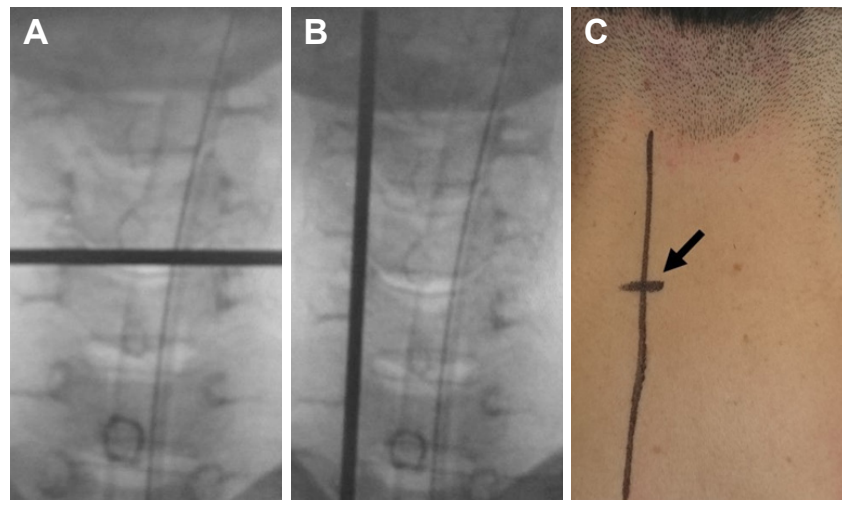

Figure 2: Intraoperative images determining the location of the skin incision. Location of the intervertebral disc at the C5/6 level (A) and the medial edge of the facet joint $(B)$ were marked as lines under intraoperative fluoroscopy. A small skin incision (C) approximately $8 \mathrm{~mm}$ in length is made at the intersection (arrow)

Statistical significance was defined as $P<0.05$ (twosided).

\section{FPCF surgical technique}

FPCF was performed according to the method of Ruetten et al. ${ }^{[17]}$ The patient was placed in the prone position under general anesthesia. In patients with pathology on the left side of C5/6, a skin incision was made under fluoroscopy at the intersection of a line at the $\mathrm{C} 5 / 6$ disc level [Figure $2 \mathrm{~A}$ ] and a line at the medial edge of the facet joint on the left side [Figure 2B]. A skin incision approximately $8 \mathrm{~mm}$ in length was made at that point [Figure 2C], and a full endoscope was inserted. The outer diameter of the entire endoscope was $6.9 \mathrm{~mm}$; the working channel was $4.2 \mathrm{~mm}$ in diameter. The angle of vision was $25^{\circ}$, and the outer diameter of the working sleeve (beveled type) was $7.9 \mathrm{~mm}$. All instruments were made by WOLF (RIWOspine $\mathrm{GmbH}$, Knittlingen, Germany).

After removal of the connective tissue attached to the vertebral lamina, the vertebral laminae at C5 and C6 were clearly exposed, and the interlaminar window 


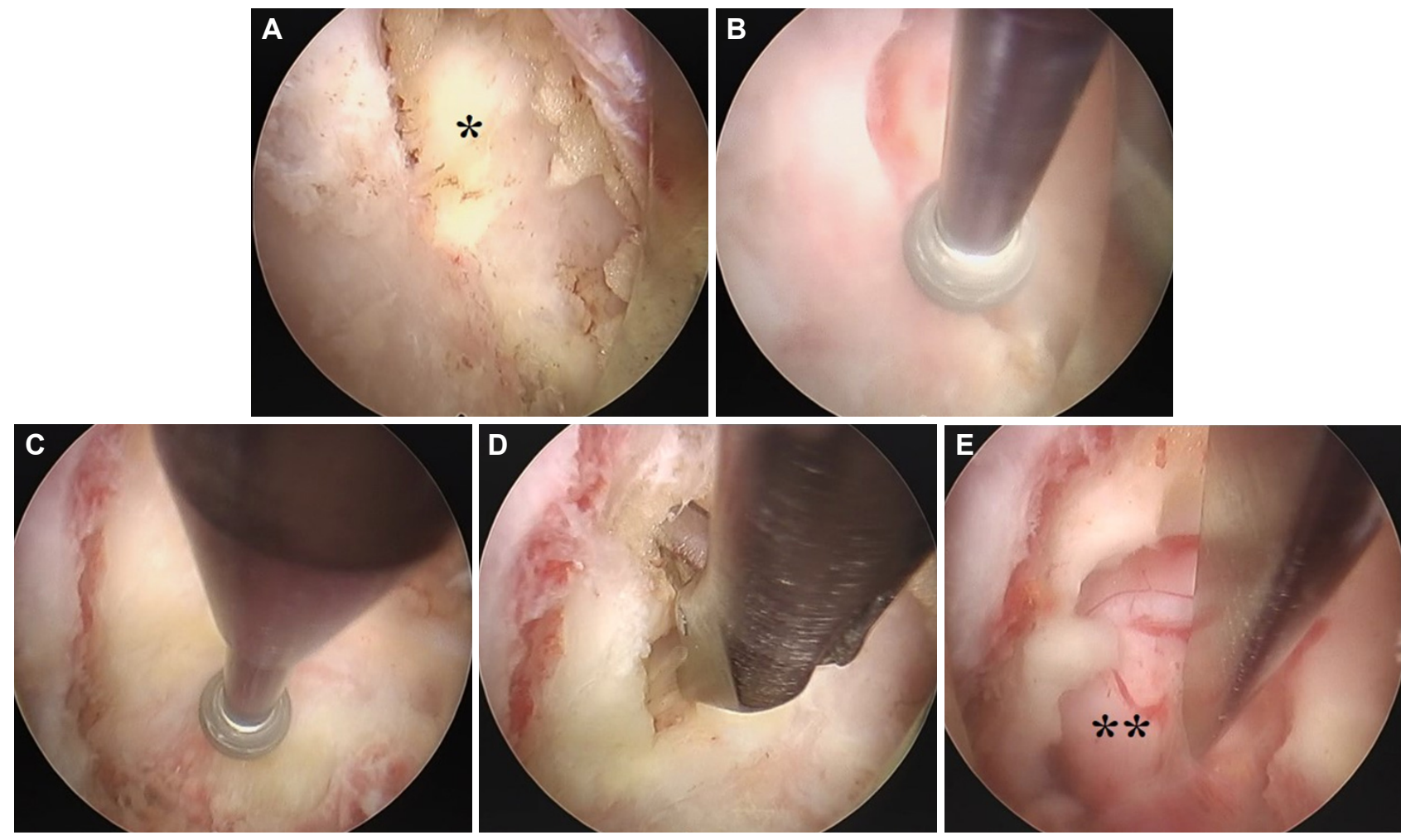

Figure 3: (A) Interlaminar window and yellow ligament $\left(^{*}\right)$ are clearly seen; (B) inferior edge of C5 vertebral lamina is partially cut with a highspeed drill; (C) superior edge of C6 vertebral lamina is also resected; (D) the yellow ligament is cut with scissors; (E) lateral edge of dura mater and C6 nerve root $\left(^{* *}\right)$ should be completely decompressed. Left side: cephalic; right side: caudal; upper side: medial; lower side: lateral

and yellow ligament were visible [Figure 3A]. First, the inferior edge of the C5 vertebral lamina was cut with a high-speed drill (NSK-Nakanishi, Kanuma, Japan) [Figure 3B], and the superior edge of the C6 vertebral lamina was cut [Figure $3 \mathrm{C}$ ]. The yellow ligament was cut and removed [Figure 3D], and the perineural membrane was carefully removed using a bipolar coagulator (Surgi-Max ${ }^{\circledR}$ Plus, Trigger-flex ${ }^{\circledR}$ System: Elliquence, LCC, Baldwin, New York, USA) with output power set to 20-25 watts. Next, the lateral edges of the dura mater and $\mathrm{C} 6$ nerve root were decompressed [Figure 3E]. After complete decompression of the nerve root, irrigation was interrupted to reveal any bleeding. If observed, hemostasis was performed with a bipolar coagulator. The wound was closed without drainage. Ideally, all operations were performed while monitoring the motor evoked potentials of the following muscles: deltoid, brachioradialis, oppenens pollicis, tibialis anterior, and gastrocnemius. Patients began walking $3 \mathrm{~h}$ after surgery.

\section{RESULTS}

Gender, age, segment, and postoperative follow-up period are shown in Table 1. No significant differences were observed between the groups in terms of gender, segment, or postoperative follow-up period. However, the mean patient age in group $\mathrm{H}$ was significantly younger than that in group $S(P<0.05)$. The average operative time in group $\mathrm{H}$ was $97.2 \pm 19.5 \mathrm{~min}$, while that in group $S$ was $102 \pm 28.9$ min. Only 2 complications occurred, both in group $\mathrm{H}$. One patient had increased radicular pain after surgery because the nerve root was stimulated during epidural hemostasis. The second had a lower lamina fracture due to cutting with the high-speed drill. In this case, a small fracture line on the $\mathrm{C} 6$ vertebral lamina was found in the coronal postoperative CT [Figure 4]. Fortunately, the patient had no symptoms. The postoperative hospital stays in group $\mathrm{H}$ and $\mathrm{Y}$ were 3.0 and 3.9 days, respectively. There were no significant differences in pre-operative neck or arm pain between the groups (neck pain: group H $51 \pm 24.1$, group $S 40.1 \pm 33$.3; arm pain: group $H$ $60 \pm 19.3$, group $S 58.3 \pm 27.1)$. On average, the neck

Table 1: Basic data of groups $\mathrm{H}$ and $\mathrm{S}$

\begin{tabular}{|c|c|c|c|}
\hline & $\begin{array}{c}\text { Group H } \\
(n=34)\end{array}$ & $\begin{array}{c}\text { Group H } \\
(n=25)\end{array}$ & $P$ \\
\hline Gender (M/F) & $24 / 10$ & $21 / 4$ & 0.15 \\
\hline Age (years) & $50(30-68)$ & $59(46-81)$ & 0.01 \\
\hline $\begin{array}{l}\text { Operated } \\
\text { spinal level }\end{array}$ & $\begin{array}{l}\mathrm{C} 4 / 5(n=6) \\
\mathrm{C} 5 / 6(n=11) \\
\mathrm{C} 6 / 7(n=15) \\
\mathrm{C} 7 / \mathrm{T} 1(n=2)\end{array}$ & $\begin{array}{c}\mathrm{C} 4 / 5(n=4) \\
\mathrm{C} 5 / 6(n=14) \\
\mathrm{C} 6 / 7(n=7)\end{array}$ & 0.50 \\
\hline $\begin{array}{l}\text { Follow-up } \\
\text { period (days) }\end{array}$ & 311 & 339 & 0.55 \\
\hline
\end{tabular}




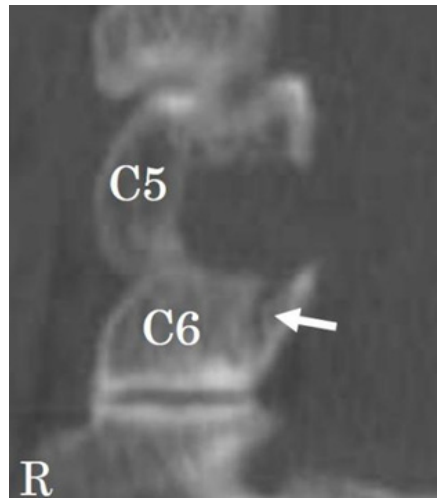

Figure 4: Postoperative computer tomography shows that vertical fracture line is on the medial side on C6 vertebral lamina (arrow). R: right side

pain VAS score at the final follow-up in group $\mathrm{H}(2.9 \pm$ 1.4) was significantly lower than that in group $S(12 \pm$ 16.4) $(P<0.05)$. However, the postoperative arm pain VAS scores were the same in both groups (group H 14 \pm 21 , group $S 14 \pm 18.6$ ). In both groups, $52 \%$ of the facet joint (group H $52 \pm 8.5 \%$, group S $52 \pm 6.7 \%$ ) was resected.

\section{Case presentation}

An 84-year-old female presented with very severe arm and neck pain on the right side. Conservative therapy was pursued for 3 months with no improvement in symptoms. Severe bony stenosis of the intervertebral foramen with spondylosis at C5/6 was observed on the sagittal and axial views of CT images [Figure 5A and B] and on the axial view on MRI [Figure 5C], and FPCF was performed. The operation time was $113 \mathrm{~min}$. The C6 nerve root and lateral margin of the dura mater on the right were completely decompressed [Figure 6]. Postoperative CT showed that the intervertebral foramen was successfully decompressed [Figure 7] and that $42 \%$ of the facet joint had been resected. The patient's VAS scores for neck and pain improved from 45.2 to 10.1 and from 63.4 to 5.2 , respectively.

\section{DISCUSSION}

Full-endoscopic spinal surgery, which is called percutaneous endoscopic spinal surgery, was first reported by Mayer and Brock ${ }^{[21]}$ for the treatment of lumbar disc herniation. Since then, surgeons have developed a percutaneous endoscopic lumbar discectomy through a transforaminal approach. ${ }^{[22-24]}$ In 2010, Choi et al. ${ }^{[25]}$ devised a new technique that approached the disc herniation through an interlaminar window. Dezawa and Sairyo ${ }^{[26]}$ further evolved the procedure using a high-speed drill. Advances in the interlaminar approach procedure have facilitated the application of full-endoscopic spinal surgery to cervical spine disease.

There are two approaches for full-endoscopic surgery in the cervical spine: anterior ${ }^{[27,28]}$ and posterior. ${ }^{[17-20]}$ Anterior percutaneous endoscopic cervical discectomy requires more careful techniques compared with FPCF. ${ }^{[28]}$ Therefore, endoscopic spinal surgeons who have performed percutaneous endoscopic lumbar discectomy find FPCF a relatively easy technique to learn. However, it has been reported that the indication for FPCF is limited to treatment of lateral disc herniation. ${ }^{[17-20]}$ To our knowledge, this is the first description of outcomes of FPCF for bony stenosis of the intervertebral foramen.

In this study, two complications were observed in groupH, both of which occurred soon after we began to perform FPCF for lateral disc herniation at our institution. There were no significant differences in the clinical parameters of operation time, length of postoperative hospital stay, arm pain VAS at the final follow-up, or percent of facet joint resection between the groups. These results suggest that FPCF is suitable for patients with bony stenosis of the intervertebral foramen. When FPCF is performed in these patients, it is very important to be careful when drilling the lamina
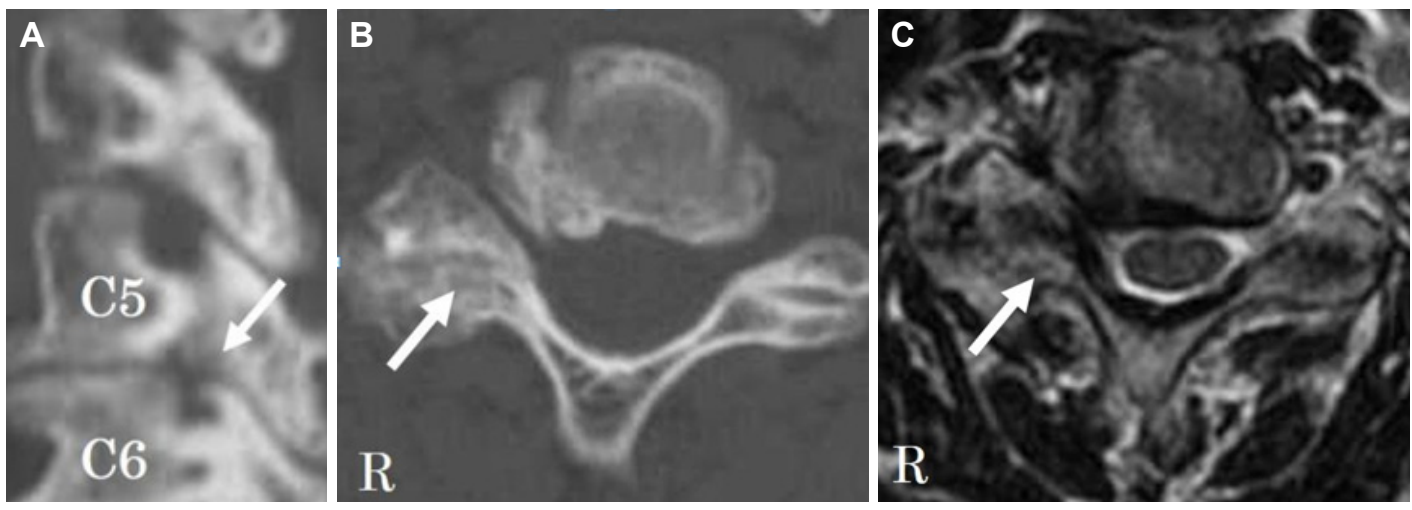

Figure 5: (A) Sagittal computer tomography (CT) reveals that the intervertebral foramen is markedly narrowed on the right side at C5/6 (arrow); (b) foraminal stenosis and deformity of the facet joint on the right side are also observed in axial CT image (arrow); (C) axial magnetic resonance imaging image also reveals that the foraminal stenosis on the right side is severe compared to that on the left (arrow). $\mathrm{R}$ : right side 


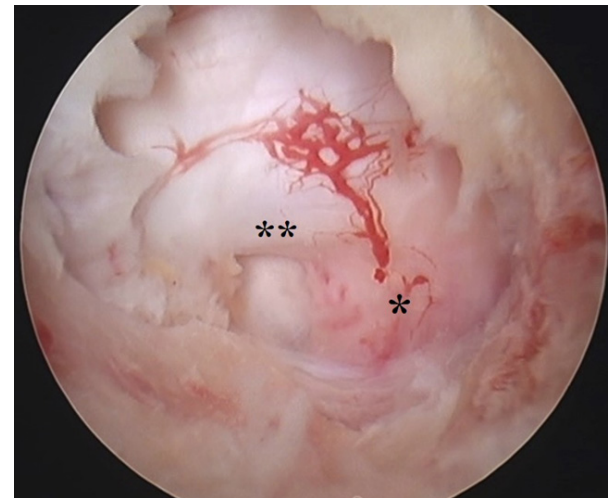

Figure 6: On the final endoscopic view in this surgery, the C6 nerve root $\left({ }^{*}\right)$ and lateral margin of the dura mater $\left({ }^{* *}\right)$ can be clearly observed. Left side: caudal; right side: cephalic; upper side: medial; lower side: lateral

because the surface of vertebral lamina is not smooth due to osteoarthrosis of the facet joint.

An average of $52 \%$ of the facet joint was resected in both groups. Although the percentage of facet joint resection affects postoperative outcomes, removing the perineural membrane of the nerve root in patients with bony stenosis of the intervertebral foramen is also key for obtaining good results because it increases nerve root mobility. The most important factor when removing the perineural membrane is to remove it piece by piece while using a bipolar coagulator.

In conclusion, we recommend that FPCF be considered for patients with radicular pain resulting from bony stenosis of the intervertebral foramen.

\section{Authors' contributions}

Conception and design: K. Ohmori

Provision and study materials or patients: K. Ohmori,

K. Ono

Collection and assembly of data: K. Ohmori, K. Ono

Data analysis and interpretation: T. Hori

Manuscript writing: K. Ohmori
Final approval of manuscript: K. Ohmori, K. Ono, T. Hori

\section{Financial support and sponsorship}

None.

\section{Conflicts of interest}

There are no conflicts of interest.

\section{Patient consent}

We obtained the patients' consent for publication of the present literature.

\section{Ethics approval}

All procedures used in the present literature approved by the Ethical Committee of Nippon Koukan Hospital.

\section{REFERENCES}

1. Bohlman HH, Emery SE, Goodfellow DB, Jones K. Robinsonanterior cervical discectomy and arthrodesis for cervical radiculopathy. Longterm follow-up of one hundred and twenty-two patients. $J$ Bone Joint Surg Am 1993;75:1298-307.

2. Brigham CD, Tsahakis PJ. Anterior cervical foraminotomy and fusion. Surgical technique and results. Spine 1995;20:766-70.

3. Cauthen JC, Kinard RE, Vogler JB, Jackson DE, DePaz OB, Hunter OL, Wasserburger LB, Williams VM. Outcome analysis of noninstrumented anterior cervical discectomy and interbody fusion in 348 patients. Spine 1998;23:188-92.

4. Fraser JF, Härtl R. Anterior approaches to fusion of the cervical spine: a metaanalysis of fusion rates. J Neurosurg Spine 2007;6:298-303.

5. Raaf JE. Surgical treatment of patient with cervical disc lesions. $J$ Trauma 1969;9:327-38.

6. Murphy F, Simmons JC, Brunson B. Surgical treatment of laterally ruptured cervical disc. Review of 648 cases, 1939 to $1972 . J$ Neurosurg 1973;38:679-83.

7. Fager CA. Management of cervical disc lesions and spondylosis by posterior approaches. Clin Neurosurg 1977;24:488-507.

8. Fager CA. Rationale and techniques of posterior approaches to cervical disk lesions and spondylosis. Surg Clin North Am 1976;56:581-92.

9. Henderson CM, Hennessy RG, Shuey HM Jr, Shackelford EG. Posterior-lateral foraminotomy as an exclusive operative technique for cervical radiculopathy: a review of 846 consecutively operated cases. Neurosurgery 1983;13:504-12.
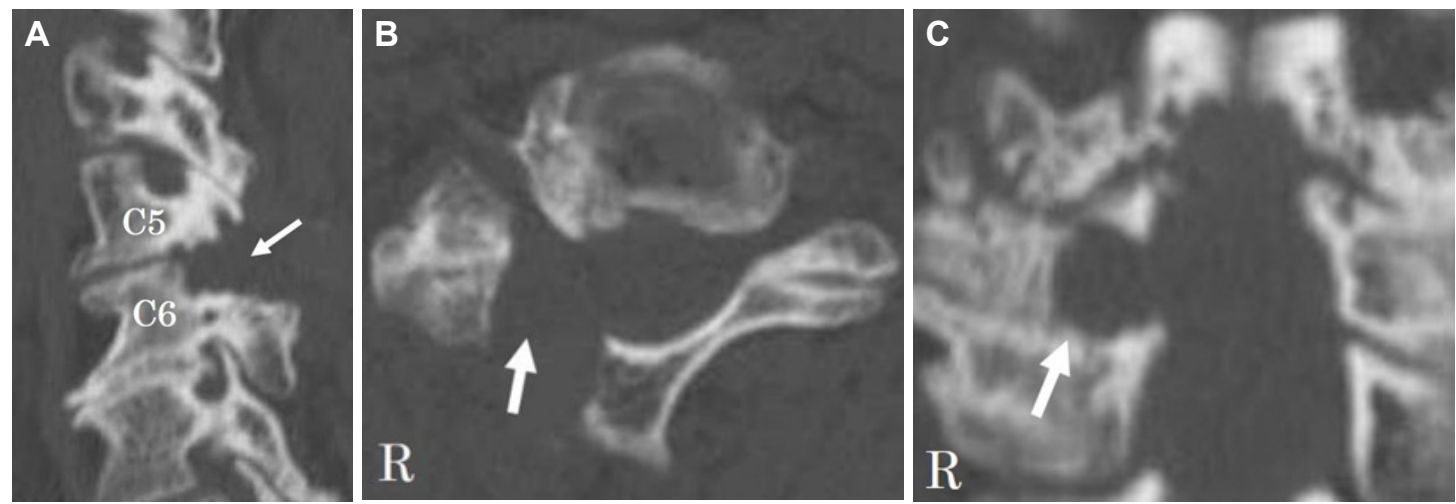

Figure 7: (A) The osteophyte, which is seen in the sagittal plane on preoperative computer tomography [Figure 5A], is completely resected (arrow); (B) the intervertebral foramen has expanded satisfactorily (arrow); (C) the percent of facet joint resection is $42 \%$ (arrow). R: right side 
10. Hilton DL Jr. Minimally invasive tubular access for posterior cervical foraminotomy with three-dimensional microscopic visualization and localization with anterior/posterior imaging. Spine J 2007;7:154-8.

11. Franzini A, Messina G, Ferroli P, Broggi G. Minimally invasive disc preserving surgery in cervical radiculopathies: the posterior microscopic and endoscopic approach. Acta Neurochir Suppl 2011;108:197-201.

12. Adamson TE. Microendoscopic posterior cervical laminoforaminotomy for unilateral radiculopathy: results of a new technique in 100 cases. J Neurosurg 2001;95:51-7.

13. Roh SW, Kim DH, Cardoso AC, Fessler RG. Endoscopic foraminotomy using MED system in cadaveric specimens. Spine 2000;15:260-4.

14. Burke TG, Caputy A. Microendoscopic posterior cervical foraminotomy: a cadaveric model and clinical application for cervical radiculopathy. J Neurosurg 2000:93:126-9.

15. Fessler RG, Khoo LT. Minimally invasive cervical microendoscopic foraminotomy: an initial clinical experience. Neurosurgery 2002;51:S37-45

16. O'Toole JE, Sheikh H, Eichholz KM, Fessler RG Perez-Cruet MJ. Endoscopic posterior cervical foraminotomy and discectomy. Neurosurg Clin N Am 2006;17:411-22.

17. Ruetten S, Komp M, Merk H, Godolias G. A new full-endoscopic technique for cervical posterior foraminotomy in the treatment of lateral disc herniation using 6.9-mm endoscopes: prospective 2-year results of 87 patients. Minim Invas Neurosurg 2007;50:219-26.

18. Ruetten S, Komp M, Merk H, Godolias G. Full-endoscopic cervical posterior foraminotomy for the operation of lateral disc herniation using 5.9-mm endoscopes: a prospective, randomized, controlled study. Spine 2008;33:940-8.

19. Kim CH, Kim KT, Chung CK, Park SB, Yang SH, Kim SM, Sung
JK. Minimally invasive cervical foraminotomy and diskectomy for laterally located soft disc herniation. Eur Spine J 2015;24:3005-12.

20. Kim CH, Shin KH, Chung CK, Park SB, Kim JH. Changes in cervical sagittal alignment after single-level posterior percutaneous endoscopic cervical diskectomy. Global Spine J 2015;5:31-8.

21. Mayer HM, Brock M. Percutaneous endoscopic lumbar discectomy (PELD). Neurosur Rev 1993;16:115-20.

22. Choi G, Lee SH, Lokhande P, Kong BJ, Shim CS, Jung B, Kim JS. Percutaneous endoscopic approach for highly migrated intracanal disc herniations by foraminoplastic technique using rigid working channel endoscope. Spine 2008;33:E508-15.

23. Lew SM, Mehalic TF, Fagone KL. Transforaminal percutaneous endoscopic discectomy in the treatment of far-lateral and foraminal lumbar disc herniations. J Neurosurg 2001;94:216-20

24. Tsou PM, Aian Yeung C, Yeung AT. Posterolateral transforamina selective endoscopic discectomy and thermal annuloplasty for chronic lumbar discogenic pain: a minimal access visualized intradiscal surgical procedure. Spine J 2004;4:564-73.

25. Choi G, Prada N, Modi HN, Vasavada NB, Kim JS, Lee SH Percutaneous endoscopic lumbar herniectomy for high-grade downmigrated L4-5 disc through an L5-S1 interlaminar approach: a technical note. Minim Invasive Neurosurg 2010;53:147-52.

26. Dezawa A, Sairyo K. New minimally invasive discectomy technique through the interlaminar space using a percutaneous endoscope. Asian J Endos Surg 2011;4:94-8.

27. Ahn Y, Lee SH, Chung SE, Park HS, Shin SW. Percutaneous endoscopic cervical discectomy for discogenic cervical headache due to soft disc herniation. Neuroradiology 2005;47:924-30.

28. Ahn Y. Percutaneous endoscopic cervical discectomy using working channel endoscopes. Expert Rev Med Devices 2016;13:601-10. 